Godt, M. W. J., J. L. HAMrick and S. Braton (1995): Genetic diversity in a threatened wetland species, $\mathrm{Hel}$ lonias bullata (Liliaceae). Conserv. Biol. 9, 596-604.

Grime, J. P., J. G. Hodgson and D. R. HunT (1988): Comparative plant ecology: a functional approach to common British species. Unwin Hyman, London.

Hamrick, J. L., M. J. W. Godt and S. L. Sherman-Broyles (1992): Factors influencing levels of genetic diversity in woody plant species. New For. 6, 95-124.

HAMRICK, J. L. and J. D. NASON (1996): Consequences of dispersal in plants, pp. 203-236 in Population dynamics in ecological space and time, edited by O. E. RoDHES, R. K. Chesser and M. H. Smith, University of Chicago Press, Chicago.

HartL, D. L. and A. G. Clark (1989): Principles of population genetics. $2^{\text {nd }}$ ed. Sinauer Associates, Sunderland, Massachusetts.

HEDRICK, P. W. (2000): Genetics of populations. $2^{\text {nd }}$ ed. Jones and Bartlet Puublishers, Sudbury, Massachusetts.

HUENNEKE, L. F. (1991): Ecological implications of variation in plant populations, pp. 31-44 in Genetics and Conservation of Rare Plants, edited by D. A. FALK and K. E. Holsinger, Oxford University Press, New York.

LESsiCA, P. and F. W. AllendoRF (1992): Are small populations of plants worth preserving? Conserv. Biol. 6, $135-139$.

McCauley, D. E. (1994): Contrasting the distribution of chloroplast DNA and allozyme polymorphism among local populations of Silene alba: implications for studies of gene flow in plants. Proc. Natl. Acad. Sci. USA. 17, 8127-8131.

MCCAUleY, D. E. (1997): The relative contributions of seed and pollen movements to the local genetic structure of Silene alba. J. Hered. 88, 257-263.

KRZAKOWA, M. and L. BEDNORZ (1999): Electrophoretic evidence of monomorphism in the Wild Service Tree, Sorbus torminalis (L.) Crantz population from 'Bytyńskie Brzęki’ preserve (western Poland). Rocz. Dendrol. 47, 45-51.

NEI, M. (1978): Estimation of average heterozygosity and genetic distance from a small number of individuals. Genetics 89: 583-590.
Oddou-Muratorio, S., B. Le Guerroue, D. Guesnet and B. Demesure (2001): Pollen-versus seed mediated gene flow in a scattered forest tree species. Evolution 55, 6, 1123-1135.

OostermeiJer, J. G. B., M. W. van EiJCK and J. C. M. DEN NIJS (1994): Offspring fitness in relation to population size and genetic variation in the rare perennial plant species Gentiana pneumonanthe (Gentianaceae). Oecologia 97, 289-296.

Petit, R. J., I. Aguinagalde, J. L. De Beaulieu, C. BitTKAU, S. Brewer, R. Chaddadi, R. EnNos, S. Fineschi, D. Grivet, M. Lascoux, A. Mohanty, G. Müller-Stark, B. Demesure-Mush, A. Palmé, J. P. Martin, S. Rendell and G. G. VendRAMIN (2003): Glacial refugia: Hotspots but not melting pots of genetic diversity. Science $\mathbf{3 0 0 0}$, 1563-1565.

PRAT, D. and C. DANIEL (1993): Variabilité génétique l'Alisier torminal et du genere Sorbus. Rev. For. Fr. 45, 3, 216-228.

Rasmussen, K. K. and J. Kollmann (2004): Poor sexual reproduction on the distribution limit of the rare tree Sorbus torminalis. Acta Oecologica 25, 211-218.

RAspé, O., A.-L. Jacquemart and J. DE Sloover (1998): Isozymes in Sorbus aucuparia (Rosaceae: Maloideae): genetic analysis and evolutionary significance of zymograms. Int. J. Plant Sci. 159, 627-636.

Rothe, G. M. (1994): Electrophoresis of Enzymes. Springer-Verlag, Berlin Heidelberg New York.

Snow, B. and D. SNow (1988): Birds and berries: a study of an ecological interaction. T\&AD Poyser, London.

WENDEL, J. F. and N. F. WEEDEN (1989): Visualization and interpretation of Plant Isozymes, pp. 5-45 in Isozymes in plant biology, edited by D. E. Soltis and P. S. Soltis, Dioscorides Press, Oregon.

Wojciechowski, A. and L. BeDNORZ (2000): Estimation of mating-compatibility of the wild service tree (Sorbus torminalis (L.) Crantz) by observing pollen tube germination. J. Appl. Genet. 41, 4, 253-258.

WRIGHT, S. (1965): The interpretation of population structure by $F$-statistics with special regard to systems of mating. Evolution 19, 395-420.

YeH, F. C., R.-C. YANG and T. Boyle (1999): POPGENE Version 1.31 Microsoft Windows-based Freeware for Population Genetic Analysis. University of Alberta.

\title{
Parental and Consensus Linkage Maps of Eucalyptus globulus Using AFLP and Microsatellite Markers
}

\author{
By J. S. Freeman ${ }^{1)}{ }^{*}$ ), B. M. Potts ${ }^{1)}$, M. ShePherD ${ }^{2)}$ and R. E. Vaillancourt ${ }^{1)}$
}

(Received $5^{\text {th }}$ January 2006)

\footnotetext{
1) Cooperative Research Centre for Sustainable Production Forestry and School of Plant Science, University of Tasmania, Private Bag 55, Hobart, Tasmania 7001, Australia.

2) Cooperative Research Centre for Sustainable Production Forestry, Centre for Plant Conservation Genetics, Southern Cross University, NSW 2480, Australia.

*) Corresponding author: email: jsfreema@utas.edu.au
}

\begin{abstract}
Parental and consensus maps were constructed in an $\mathrm{F}_{2}$ inter-provenance cross of Eucalyptus globulus, using amplified fragment length polymorphism (AFLP) and microsatellite (or simple sequence repeats [SSR]) markers. The female map had 12 linkage groups and 118 markers, comprising 33 SSR and 85 AFLP loci. The
\end{abstract}


male map had 14 linkage groups and 130 markers comprising 36 SSR and 94 AFLP loci. The integrated map featured 10 linkage groups and 165 markers, including 33 SSR and 132 AFLP loci, a small $11^{\text {th }}$ group was identified in the male parent. Moderate segregation distortion was detected, concentrated in gender specific groups. The strongest distortion was detected in the female parent for which causal mechanisms are discussed. The inclusion of SSR markers previously mapped in several different eucalypt species within the subgenus Symphyomyrtus (E. globulus, E. camaldulensis, and predominantly $E$. grandis and $E$. urophylla), allowed comparison of linkage groups across species and demonstrated that linkage orders previously reported in $E$. globulus, E. grandis and E. urophylla were largely conserved.

Key words: Linkage map, Eucalyptus globulus, SSR, AFLP, comparative mapping.

\section{Introduction}

Eucalyptus globulus is one of the most commercially important plantation tree species in temperate regions of the world (ELDRIDGE et al., 1993). As a result, breeding programmes have been established in order to produce genetically superior E. globulus trees (PoTTs et al., 2004). Linkage maps and associated molecular markers can be useful in tree improvement programmes as prerequisites for the study of quantitative traits using the quantitative trait loci (QTL) approach (GRATTAPAGLIA, 1997, 2000; AHUJA, 2001). Consequently, linkage maps have been produced for many forest tree genera of economic importance including Eucalyptus (e.g. BYRNE et al., 1995), Pinus (e.g. Plomion et al., 1995), Poplar (e.g. BradshaW and StetTler, 1994) and Acacia (Butcher et al., 2002).

Molecular maps produced in tree species have employed a variety of DNA marker classes, each having their merits (reviewed by CERVERA et al., 2000). For example, AFLP (Vos et al., 1995) are anonymous and dominant markers, based on arbitrarily selected PCR primers that require no a priori sequence knowledge, primer or probe development. The AFLP technique has the highest multiplex ratio of any PCR based technique (MYBURG et al., 2001), allowing the production of high coverage parental maps in various plants including interspecific crosses of eucalypts such as E. tereticornis $\mathrm{x}$ $E$. globulus (MARQUES et al., 1998) and E. grandis $\mathrm{x}$ E. globulus (MYBURG et al., 2003). However, dominant markers will predominantly be mapped to one parent, hence often co-dominant markers must be included to merge parental maps (GRATTAPAGLIA, 2000). Similarly, the transferability of AFLP is often low, even within species (CERVERA et al., 2000).

SSR markers have many attributes suitable for map construction (CERVERA et al., 2000). They are multi-allelic, usually highly polymorphic and co-dominant in their inheritance (AvISE, 1994). However SSR markers require considerable investment in primer development, limiting their availability. For example, the limited availability of SSR primers for Eucalyptus has, until recently, made the construction of maps based solely on these markers unfeasible. In order to remedy this prob- lem, AFLP markers can be used to provide high density maps upon which to map co-dominant markers, such as SSRs (e.g. CERVERA et al., 2001).

Importantly, SSRs are often highly transferable between pedigrees and species (JONES et al., 2001; STEANE et al., 2001; MARQUES et al., 2002), allowing integration of parental maps, comparative mapping and ultimately the construction of species consensus maps (GRATTAPAGLIA, 2000). The comparison of genetic linkage maps based on a common set of markers allows the identification of homologous loci and collinear chromosome segments between species. Comparative maps have demonstrated a high degree of co-linearity for numerous plant species including tomato and pepper, wheat and rice, and pine species Pinus taeda and Pinus radiata (AHUJA, 2001). Similarly, in eucalypts, the mapping of interspecific hybrid progeny has allowed the demonstration of a high degree of synteny between maps of $E$. grandis and $E$. urophylla (BRONDANI et al., 1998; 2002), E. grandis and E. globulus (MYBURG et al., 2003), and E. grandis, E. urophylla, E. tereticornis and E. globulus (MARQUES et al., 2002). The apparent genome conservation between many of the economically important eucalypt species within the subgenus Symphyomyrtus suggests that the construction of a consensus map for the subgenus will be attainable (BRONDANI et al., 2002; MARQUES et al., 2002).

Comparative mapping and ultimately the construction of a consensus map for the genus will be invaluable for molecular breeding and more fundamental research, such as studying genome evolution and genetic differentiation in Eucalyptus. In the area of molecular breeding, comparative mapping would enable the exchange and comparison of information between studies world-wide in areas such as QTL mapping, candidate gene mapping and marker assisted selection (BRONDANI et al., 2002). In particular, comparative mapping will allow the validation of putative QTL over different genetic backgrounds (e.g. MARQUES et al., 2002), providing a basis for effective marker assisted selection (MAS) (BRONDANI et al., 2002).

Forest trees such as Eucalyptus are generally characterised by long generation times, high levels of genetic diversity and an absence of multi-generation pedigrees or inbred lines (SEWELL and NEALE, 2000). Long generation times and an absence of multi-generation pedigrees in particular, combined with the large areas required for progeny trials, have limited the establishment of large advanced generation crosses which are most useful for the production of linkage maps. Most maps produced have utilised interspecific $\mathrm{F}_{1}$ material and markers segregating in a double pseudo-testcross configuration, taking advantage of the high levels of heterozygosity found in eucalypt species (GRATTAPAGLIA and SEDEROFF, 1994; Verhaegen and Plomion, 1996; MARques et al., 1998; AGRAMA et al., 2002). Fewer studies have utilised $\mathrm{F}_{2}$ crosses with grandparents from widely disjunct localities (BYRNE et al., 1995) or interspecific hybrids (MYBURG et al., 2003). In contrast to the majority of previous mapping experiments in eucalypts, this study utilised markers segregating in an $\mathrm{F}_{2}$ progeny to map 
the $\mathrm{F}_{1}$ parents from a wide intraspecific cross. The widely separated provenances of origin and three generation design of this cross promotes polymorphism by capturing the differences between eucalypt populations. The increased polymorphism increases the likelihood of QTL segregating in this pedigree.

The aim of this study was to produce parental and consensus maps in an outbred, $\mathrm{F}_{2}$ interprovenance cross of E. globulus, using AFLPs and predominantly fully informative SSR loci. The mapping of fully informative SSR loci derived from a variety of sources (EMBRA, CSIRO, EMCRC), allowed comparison of synteny and collinearity of shared markers between this study and maps previously produced in a range of eucalypts from the subgenus Symphyomyrtus (BRONDANI et al., 1998, 2002; BundOCK et al., 2000; MARQUES et al., 2002; ThAmARUs et al., 2002). As such, these maps provide a contribution toward the production of reference maps for $E$. globulus and the subgenus. The linkage maps produced in this study will also be used to investigate marker trait associations (QTL) for the genetic control of important economic traits, including resistance to fungal pathogens from the genus Mycosphaerella.

\section{Molecular methods}

\section{Plant material}

The mapping population consisted of an outbred, $\mathrm{F}_{2}$ full sib family derived from an inter-provenance cross. The four grandparents were from two widely separated locations in Tasmania - King Island, situated to the northwest of Tasmania and Taranna in the far southeast (Fig. 1). Trees from these locations are classified into different geographical races, differentiated by numerous quantitative traits (DUTKOwski and PoTTS, 1999). Crossing between unrelated grandparents from King Island and Taranna produced each $\mathrm{F}_{1}$, which were then crossed to produce the $\mathrm{F}_{2}$ (Fig. 2). These grandparents were chosen in order to maximise the segregation of quantitative characters that differ between provenances, such as resistance to Mycosphaerella sp. (CARNEGIE et al., 1994). Seedlings were planted in a randomised incomplete block design, at Woolnorth in northwest Tasmania in May 1998. Originally 240 genotypes from the cross were planted with 160 genotypes repre-



Figure 1. - Origins of the grandparents of the mapping pedigree in Tasmania, Australia.

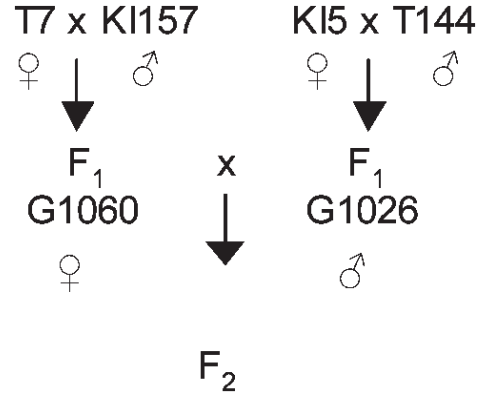

Figure 2. - Pedigree of the mapping population. 'T' indicates grandparents of Taranna origin, 'KI' indicates King Island (see Fig. 2.2). (The grandparents correspond to those used by HoDGE et al., 1996; T7 = h, KI157 = 19, KI5 = c, T144 = 6).

sented by two clonal replicates. This cross suffered a high mortality (28\%), and leaf tissue was collected in April 2001, only from the 121 different $\mathrm{F}_{2}$ genotypes that had both clonal replicates surviving.

Total genomic DNA was extracted from $1 \mathrm{~g}$ of fresh leaf tissue, using a CTAB extraction protocol (DoYLE and DOYLE, 1990). Following extraction, DNA samples were cleaned using Prep-a-Gene matrix purification (BioRad). DNA concentration and purity were estimated using agarose gel electrophoresis with ethidium bromide staining, by comparison with a standard molecular weight marker (lambda Hind III). Samples were diluted 1:4 in de-ionised water for PCR amplification.

\section{SSR Analysis}

The parents of the mapping cross were initially screened with three sets of SSR primers: 233 from EMBRA (BRONDANI et al., 1998; 2002), 13 from EMCRC (STEANE et al., 2001) and 34 from CSIRO (BYRNE et al., 1996 and http://www.ffp.csiro.au/tigr/molecular/ eucmsps.html). Loci segregating in both parents were preferentially selected to screen the progeny of the mapping cross. The details of primer sequences and reagents for the EMCRC SSRs are those given by STEANE et al. (2001) and conditions for the CSIRO SSRs are given by BYRNE et al. (1996). All SSR PCR reactions were carried out in $12.5 \mu \mathrm{l}$ (final volume) reactions. The volume of each primer was elevated from $0.2 \mu \mathrm{M}$ to $0.3 \mu \mathrm{M} / \mathrm{reac}-$ tion for the CSIRO SSRs. The PCR reagents used for the amplification of the EMBRA microsatellites are essentially those of BRONDANI et al. (1998) with the following modifications: $0.1 \%$ Triton X-100, $0.1 \mathrm{mg} / \mathrm{mL}$ BSA and no DMSO. Primer sequences and recommended annealing temperatures for EMBRA loci 1-20 are given by BRONDANI et al. (1998), for EMBRA 21-70 by BRONDANI et al. (2002) and for EMBRA 75-240 by BRONDANI (2001). EMCRC primers were synthesised with a fluorescent label (either HEX or TET) attached to the 5' end to allow detection of PCR products by a Gel Scan 2000 real-time acrylamide gel system (Corbett Research). The EMBRA and CSIRO markers incorporated a fluorescently labelled dUTP at $0.6 \mu \mathrm{mol} / \mathrm{PCR}$ reaction (Chromatide $^{\mathrm{TM}}$ tetramethylrhodamine-6-dUTP, Molecular Probes) for Gel Scan 2000 detection. PCR reaction conditions of microsatellite loci often required optimisation for detection using the Gel Scan 2000, by slight modifi- 
cation of the recommended annealing temperature or $\mathrm{MgCl}_{2}$ content (Appendix).

All microsatellite loci were amplified using the same amplification conditions; an initial denaturation step at $94{ }^{\circ} \mathrm{C}$ for 2 minutes, followed by 30 cycles of $94{ }^{\circ} \mathrm{C}$ for 1 minute, annealing temperature for 1 minute, and an extension step at $72{ }^{\circ} \mathrm{C}$ for 1 minute. Following the 30 cycles there was a final extension step of $72{ }^{\circ} \mathrm{C}$ for 5 minutes. A 'touchdown' PCR was used to enhance the quality of PCR products, with the annealing temperature dropping by $2{ }^{\circ} \mathrm{C}$ every 10 cycles. Annealing temperature varied within and between primer sets (Appendix).

Microsatellite fragments were separated on $15 \mathrm{~cm} 4 \%$ polyacrylamide gels, using a Gel Scan 2000. Gel analysis was performed using Gene Profiler ${ }^{\mathrm{TM}}$ software (Scanalytics, Inc.) by comparison to a Promega (CXR) 60-400 base fluorescent ladder, allowing a semi-automated scoring of individuals.

\section{AFLP analysis}

The method adopted for AFLP generation essentially followed the protocol of Vos et al. (1995), with minor adjustment for eucalypt DNA after MARQUES et al. (1998). The standard procedures were modified to allow restriction of genomic DNA and ligation of adaptors in a single step, with detection of fragments by a Gel Scan 2000 (see below). The DNeasy plant mini kit (Qiagen) was used to extract total genomic DNA (from $0.1 \mathrm{~g}$ of leaf tissue/sample) in order to provide the high purity required for thorough and even restriction of each sample. DNA concentration was estimated by comparison with lambda Hind III DNA standard on $1.5 \%$ agarose gels. Samples were diluted in de-ionised water to 20 $\mathrm{ng} / \mathrm{\mu l}$.
Initially, test cuts were performed with each restriction enzyme ( $E c o$ RI and $M s e I$ ) separately to ensure each achieved complete digestion across all samples, assessed by electrophoresis on $1.5 \%$ agarose gels with ethidium bromide staining. The restriction of genomic DNA and ligation of adaptors were performed in a single reaction. In 96 well polycarbonate plates $250 \mathrm{ng}$ of genomic DNA was added to the restriction-ligation mixture and incubated at $37^{\circ} \mathrm{C}$ overnight. The reagents for the restriction-ligation reaction $(30 \mu \mathrm{l}$ final volume) were as follows: 3.9 U EcoRI (ie. 5 U/40 $\mu \mathrm{l}$ ) (New England Biolabs), 3.9 U MseI (New England Biolabs), 0.6 U T4 Ligase (Promega), 1 x T4 Ligase buffer (Promega), $1.5 \mu \mathrm{g}$ BSA, $0.05 \mathrm{M} \mathrm{NaCl}, 3 \mathrm{pM}$ EcoRI adaptor, $30 \mathrm{pM} M s e I$ adaptor.

The reagents for pre-selective and selective amplification were as described by Vos et al. (1995). The thermocycling conditions for the pre-selective amplification were adapted from Vos et al. (1995) to promote selectivity (MARQUES et al., 1998). The selective thermo-cycling conditions followed Vos et al. (1995). Primers with the optimum number of selective bases for pre-selective and selective amplification of eucalypt DNA (one and three respectively; MARQUES et al., 1998) were employed for AFLP reactions. Pre-selective primers were from MARQUES et al. (1998) (EcoRI +A, MseI +C). Substantial variability in the number of bands produced by different primer combinations $(E c o R I+3, M s e I+3)$ in the selective amplification warranted a preliminary screening of 40 primer combinations, including 22 from MARQUES et al. (1998), to allow the most informative to be employed for progeny screening (Table 1). The selective EcoRI (+3) primers were fluorescently labelled with TET for detection by the Gel Scan 2000.

AFLP samples from the selective amplification were combined with two volumes of formamide B-blue loading

Table 1. - The number of polymorphic AFLP amplification products generated over 21 different primer combination. $E c o+3$ and $M s e+3$ columns indicate selective nucleotides at the ends of the oligonucleotide primers in the selective PCR. All primer combinations except those indicated by * are from MARQUES et al. (1998).

\begin{tabular}{cccc}
\hline $\begin{array}{c}\text { Primer } \\
\text { combination }\end{array}$ & Eco +3 & Mse +3 & $\begin{array}{c}\text { Total number of } \\
\text { polymorphic bands }\end{array}$ \\
\hline 1 & ACA & CCA & 6 \\
2 & ACA & CTC & 5 \\
3 & ACA & CAG & 18 \\
4 & ACA & CAC & 11 \\
5 & ACA & CCC & 5 \\
6 & ACA & CCT & 13 \\
7 & AAA & CCG & 7 \\
8 & AAA & CGA & 28 \\
9 & AAC & CCC & 12 \\
10 & AAC & CCT & 14 \\
11 & AAG & CCG & 13 \\
12 & AAG & CGG & 12 \\
13 & AAG & CTG & 20 \\
14 & ATG & CCA & 11 \\
15 & ACC & CCA & 12 \\
16 & AAG & CCT & 12 \\
17 & AAC* & CGA* & 7 \\
18 & ACA & CGA* & 10 \\
19 & ATC* & CGA* & 10 \\
21 & AAC* & CAG* & 6 \\
22 & ACT & CCA & 11 \\
& & & 11.6 \\
\hline
\end{tabular}


buffer (formamide with the addition of $0.1 \mathrm{mg} / \mathrm{mL}$ bromophenol blue sodium salt) and denatured for 2 minutes at $94^{\circ} \mathrm{C}$, then rapidly cooled on ice. Subsequently, AFLP fragments were separated by electrophoresis on $15 \mathrm{~cm} 6 \%$ denaturing acrylamide gels, using a Gel-Scan 2000 real-time acrylamide gel system. Electrophoresis at $40^{\circ} \mathrm{C}$ and 12000 volts for 90 minutes allowed separation of bands ranging from approximately 50-450 bp in size. Bands were scored manually by comparison to a Promega (CXR) 60-400 base fluorescent ladder, utilising Gene Profiler ${ }^{\mathrm{TM}}$ software. Only bands that were clear and unambiguous across the entire mapping population were scored. Subsequently, the 'Match bins' function of the Database manager within the Gene Profiler ${ }^{\mathrm{TM}}$ software was used to automatically generate presence/ absence binary scores for each sample across all scored bands with match tolerance set at $0.5 \%$. AFLP fragments were given a three-point confidence rating denoting their quality and ease of scoring as described by SHEPHERD et al. (2003).

\section{Linkage analysis}

Following scoring, all microsatellite and AFLP gels were checked visually for scoring errors. All loci were recoded by their segregation type, according to the cross pollinated coding scheme and separated into male and female datasets for analysis by Joinmap 3.0 (VAN OOIJEN and VoORRIPS, 2001). The Joinmap 3.0 package allows the integration of data with various segregation types, and recombination estimates from a variety of sources into a single map (VAN OOIJEN and VOORRIPS, 2001). Each data set included the parental genotypes at all loci (grandparental genotypes and linkage phase information were not included), with Joinmap 3.0 automatically calculating the linkage phase of each marker when calculating pair-wise recombination frequencies.

All loci were tested for goodness of fit to expected Mendelian segregation ratios using Chi-square goodness of fit tests. AFLP loci were expected to follow segregation ratios of 3:1 (each parent heterozygous for the presence of the band) or 1:1 (band heterozygous in one parent only). The 3:1 segregating loci were given a classification code in the locus file to instruct the programme to test for this segregation ratio, allowing for dominance. Most mapped SSR loci were fully informative, segregating in approximate ratios of 1:1:1:1 (either heterozygous in both parents with 3 alleles in total, or heterozygous in both parents with 4 alleles in total). The only mapped SSR loci that followed approximate segregation ratios of 1:1 (heterozygous in only one parent), were EMBRA 6, 78, 197 and EMCRC 2 from the male parent and EMBRA 208 from the female parent.

The Joinmap 3.0 programme initially groups loci that are significantly associated (linked) on the basis of a LOD score. Groupings are derived from the test for independence of loci in a contingency table, which are then converted to a LOD score (VAN OOIJEN and VOORRIPS, 2001). There is a theoretical basis for selecting associations at different LOD values, based upon genome size and the number of linkage tests (KEATs et al., 1991), however, an intuitive approach is often used in order to select a LOD score at which the contents of most groups are relatively stable. Joinmap 3.0 is particularly suited to such an approach, by allowing the user to view the stability of groupings over a range of LOD thresholds simultaneously in tree format.

During the mapping procedure, Joinmap 3.0 uses a weighted least squares approach to sequentially build a map from pair-wise data. Within linkage groups, the maximum recombination frequency, and the minimum LOD score determines the stringency of marker ordering. Selecting a lower recombination frequency and/or higher LOD will increase the stringency of mapping by excluding more loci from the map calculations. Within these parameters, the chi-square jump threshold restricts the allowable increase in 'goodness-of-fit' after the inclusion of a particular marker to an existing order. The lower the chi-square jump threshold the greater the stringency of marker ordering, with values of 3-5 recommended (VAN OOIJEN and VOORRIPS, 2001). The genotype probability function indicates the number of genotypes with a low probability, conditional upon the map and surrounding markers, thereby highlighting markers with possible genotyping errors.

Linkage groups in the comprehensive parental maps were assigned with a minimum LOD threshold of 4.0 for the male parent and 3.0 for the female parent. Within linkage groups, marker order was determined using Joinmap 3.0 default values of a minimum LOD threshold of 1.0, and a maximum recombination threshold of 0.4. In order to produce a map with robust marker order, a stringent maximum Chi-square goodness of fit jump threshold of 1.2 was used for all loci with the exception of EMBRA 6 which was placed at 1.8. The Kosambi mapping function was used to determine distance between markers.

Linkage analysis was conducted on male and female datasets independently, before merging parental maps into an integrated map. Parental maps were constructed in several stages. The analysis was initially conducted with the highest quality markers to establish a 'trusted order' including most SSR and AFLPs segregating 1:1. Subsequently, the data were reanalysed adding the markers of lower quality in three steps: the lowest ranking AFLP loci segregating 1:1, dominant AFLPs and all loci with segregation distortion with $\alpha \leq 0.05$. At each stage the order of markers was checked against the established order from the best markers and each parent against the other, the lower quality markers were accepted if they fitted the trusted order within the designated parameters (above). Where marker order changed following the inclusion of lower quality data, markers were dropped from the data set on the basis of their quality ranking (AFLPs), Chi-square goodness of fit jump contribution and genotype probability ranking. Once all markers fitting the designated parameters had been added and homology was established between the orders of shared markers in parental maps, an integrated map was produced based on shared markers. Markers were included in the integrated map where locus order agreed with parental maps. The fixed order option was used to reduce chi-square jumps in the construction of the integrated map for groups 7 and 8 in order to achieve agreement with the trusted marker order from 
Table 2. - The amplification success and polymorphism of SSR loci by source.

\begin{tabular}{lrrrrrr}
\hline \multirow{2}{*}{ Source } & No. & No. & \multicolumn{4}{c}{ Polymorphism } \\
\cline { 3 - 7 } & tested & Neither & Male & Female & Both \\
& 233 & 129 & 31 & 19 & 14 & 65 \\
EMBRA & 23 & 12 & 1 & 3 & 3 & 5 \\
EMCRC & 13 & 12 & 3 & 2 & 2 & 17 \\
CSIRO & 34 & 24 & 35 & 24 & 19 & 87 \\
Total & 280 & 165 & & &
\end{tabular}

parental maps. Final marker orders were accepted when there was agreement between all maps within the designated parameters, giving a high degree of confidence in locus ordering. The numbering of linkage groups 1-11 (where present), in all maps followed BRONDANI et al. (1998, 2002, and unpublished data), in order to facilitate a comparison of linkage group homology.

Genotyping errors can lead to difficulty in locus ordering and inflated map lengths. In order to detect mistyped markers, numerous linked loci that exceeded the threshold Chi-square goodness of fit contribution, or displayed excessive double crossovers (evidenced by low genotype probability), were checked (using the original gel image for SSR loci, or quality rating for AFLP markers) for the robustness of scoring and either excluded from mapping analysis, or added as accessories to indicate a lower confidence in their placement relative to framework markers. Accessory markers were located on the parental maps next to their nearest framework marker by their minimum recombination frequency and LOD score. Accessory markers were not included in the integrated linkage map, unless placed as a framework marker in one parent.

\section{Results}

\section{Marker analysis}

Twenty-one of the 40 AFLP primer combinations screened were employed for genotyping, including 17 from MARQUES et al. (1998) (Table 1). These combinations amplified 243 polymorphic bands in total, an average of 11.6 polymorphic bands per primer combination. One hundred and eighty four bands segregated in an approximate 1:1 ratio, comprising 87 from the female parent and 97 from the male parent. Fifty-nine bands segregated from both parents in an approximate 3:1 ratio.

Table 2 provides a summary of the results of screening the SSR loci. In total 165 of the 280 loci screened were able to be amplified in this $E$. globulus cross. The relative success of each set of loci reflected taxonomic distance from the species in which they were developed. Of the EMCRC loci (from E. globulus) 92\% were amplifiable, compared with only $71 \%$ of CSIRO loci (from $E$. globulus and the closely related $E$. nitens), and only $55 \%$ of EMBRA loci, (developed from the more distantly related $E$. grandis / $E$. urophylla). Of the 165 amplifiable SSR loci, 24 (15\%) segregated exclusively from the male parent, 19 (12\%) from the female parent only, $87(53 \%)$ from both parents and were thus fully informative (Table 2), while $35(21 \%)$ were not heterozygous in either parent.

\section{Linkage analysis}

For the female parent (G1060; Figure 3a), twelve linkage groups (comprising one or more SSR or at least three AFLP loci) were defined by two-point linkage analysis at a minimum LOD score of 3.0. There were 106 framework markers, with 12 accessory markers added to make the comprehensive map, comprising 33 SSR and 85 AFLP loci (Figure $3 a$ ). Eleven markers were unlinked and 65 markers were excluded during map construction, because they did not fit the trusted order within the designated mapping parameters. Total map length was $698.3 \mathrm{cM}$. Linkage groups ranged in size from $2 \mathrm{cM}$ (group 13), to $97.2 \mathrm{cM}$ (group 1) with the average size being $58.2 \mathrm{cM}$. The 118 markers mapped to 117 positions separated by 105 intervals with an average size of $6.6 \mathrm{cM}$. The maximum interval between markers was $33.4 \mathrm{cM}$ (group 5).

For the male parent (G1026; Figure 3b), fourteen linkage groups were defined at a minimum LOD score of 4.0 and comprised three or more loci. Two groups (group 2'; Figure $3 b$ ) correspond to linkage group 2 in the female parent, identified by fully informative SSR that were linked in the female parent and integrated map. These two groups united at LOD 3.0. However, the locus order of the resultant group departed from the established trusted order and was thus not accepted. The 14 linkage groups included 121 framework and 9 accessory markers, comprising 36 SSR and 94 AFLP loci (Figure 3b). Twenty markers were unlinked and 57 markers were excluded during map construction, because they did not fit the trusted order within the designated mapping parameters. Total map length was $775.5 \mathrm{cM}$, with linkage groups ranging in size from $113.7 \mathrm{cM}$ (group 3) to $6.9 \mathrm{cM}$ (group 9). The average size of linkage groups was $55.4 \mathrm{cM}$. The 130 markers mapped to 127 positions separated by 113 intervals with an average size of $6.9 \mathrm{cM}$. The maximum interval between markers was $28.6 \mathrm{cM}$ (group 4).

SSR and AFLP loci segregating from both parents (Table 3) allowed the construction of an integrated map (Figure 3c). The integrated map featured 165 markers in 10 groups with a total map length of $701.9 \mathrm{cM}$. Thirtyseven of the markers in the integrated map had been placed in both parental maps, comprising 28 SSR and 9 AFLP, allowing the identification of homology between parental maps for ten linkage groups. A small $11^{\text {th }}$ group (9') was identified in the male parent. The 165 markers comprised 33 SSR and 132 AFLP loci. Markers that segregated bi-parentally were placed by the average of their recombination ratio. Despite the greater number of mapped markers segregating from the male parent, no significant difference was observed in recombination frequencies among consecutive pairs of fully informative loci at a threshold $\alpha=0.05$.

\section{Segregation distortion}

The proportion of markers exhibiting significant distortion from expected Mendelian segregation ratios were greater than would be expected by chance alone, for both parental maps. Loci that departed from expected segregation ratios were included in maps on the basis of 
4
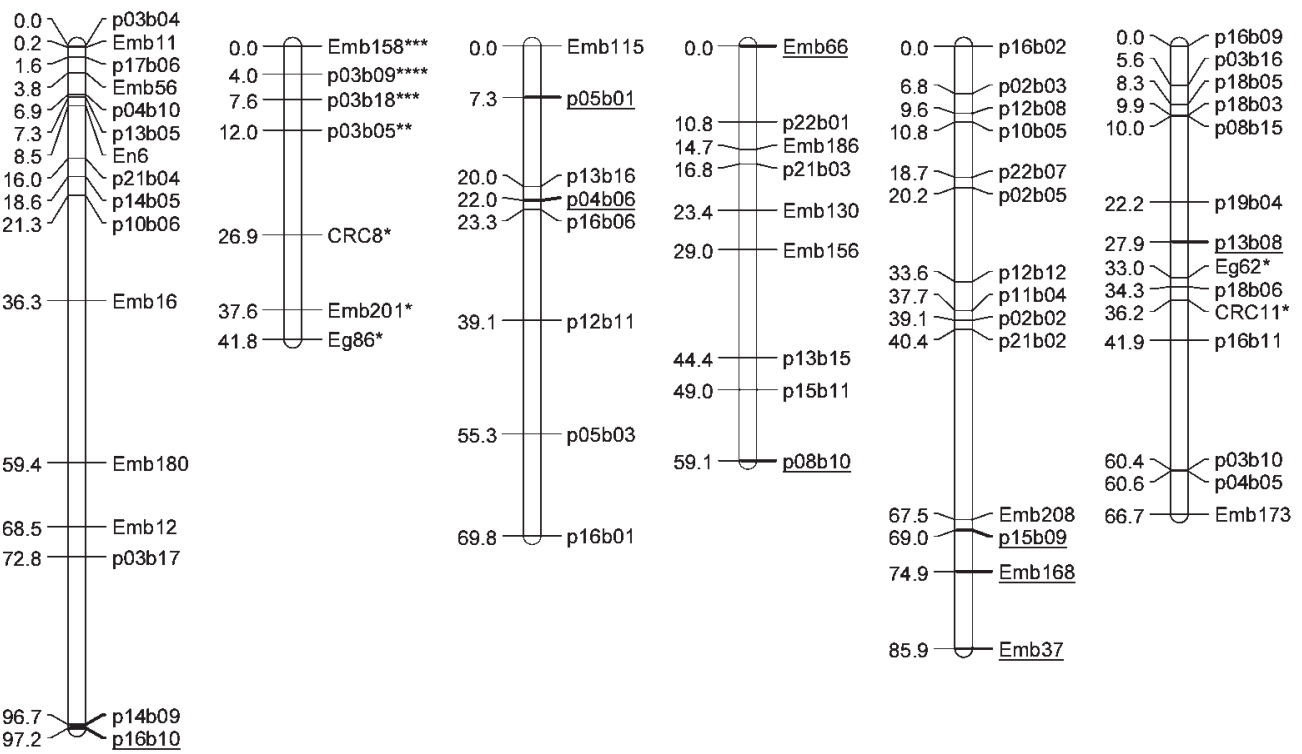

11
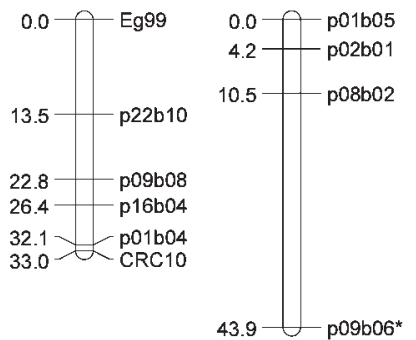

13

$2.0-204 \mathrm{~b} 0$
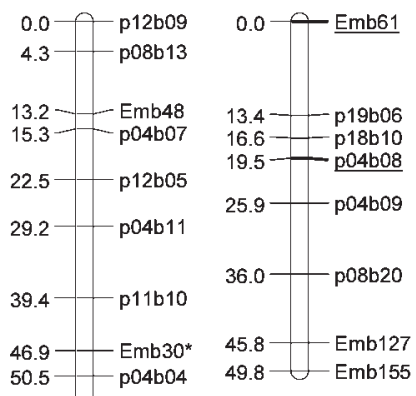

$33.0-2$ CRC10

12

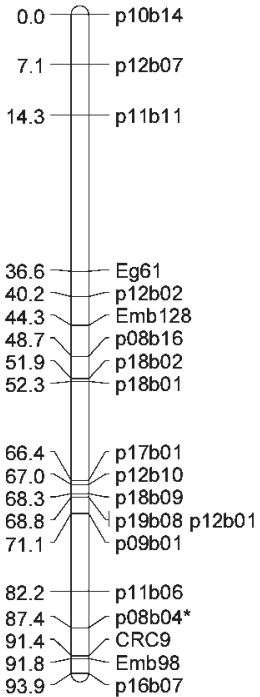

Figures 3(a-c). - Linkage maps of Eucalyptus globulus using SSR and AFLP markers. Linkage groups are numbered following Brondani et al. 1998 and 2002. The distance between markers is indicated in Kosambi centimorgans. SSR markers are preceded by EMB (EMBRA), En or Eg (CSIRO, Isolated from E. nitens, or E. globulus respectively) or CRC (EMCRC) to indicate their source. AFLP markers are labelled p\#b\# with numbers indicating the primer combination ( $\mathrm{p \#}$ ) and band number (b\#) respectively. Accessory markers are underlined, loci with distorted segregation ratios are indicated by asterisk; $* \mathrm{P} \leq 0.05$, ** $\mathrm{P} \leq 0.01$, *** $\mathrm{P} \leq 0.001$, $* * * * \mathrm{P} \leq 0.0001$.

Figures 3(a). - Linkage map of the female parent.

fitting the 'trusted order' without substantial re-ordering, and conformation to the designated mapping parameters (see Materials and Methods). The proportion of mapped markers with distorted segregation $(\alpha \leq 0.05)$ was greater for the female $13(11 \%)$ than the male 12 (9\%) parental maps, however this difference was not significant $\left(X_{1 \mathrm{~d}}^{2}=0.2178, \mathrm{P} \leq 0.05\right)$.
More significant distortion also occurred on the female map, where one marker (p03b09) was distorted at $\alpha \leq 0.0001$, one marker at $\alpha \leq 0.0005$ (p03b18), one marker at $0.005 \%$ (EMBRA 158) and one marker at $\alpha \leq 0.01$ (p03b05). The remaining nine markers were distorted at $\alpha \leq 0.05$. In contrast, only one marker was distorted at $\alpha \leq 0.005 \%$ in the male map (EMBRA 158), 
with the remaining 11 markers distorted at $\alpha \leq 0.05$ (Figures $3 a$ and $3 b$ ).

Distorted markers $(\alpha \leq 0.05)$ mapped to 5 linkage groups in the female parent and 5 linkage groups in the male parent. The distribution of distorted markers was concentrated, on two linkage groups (male 5 and female
2 ), other distorted markers occurred singly or scattered within linkage groups (Figures $3 a$ and $3 b$ ). The most severe distortion occurred on linkage group 2 , where all markers from the female parent exhibited segregation distortion (Figure 3a). A gradient was evident in the distortion ratios from a maximum $\alpha=0.0001(0.01 \%)$, in
1

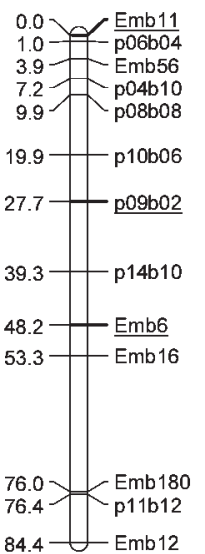

6

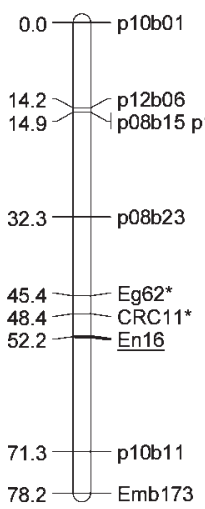

12
3

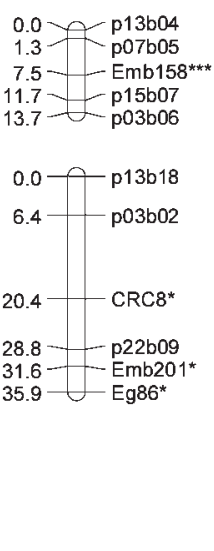

7

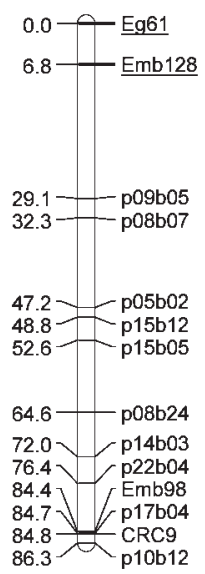

4

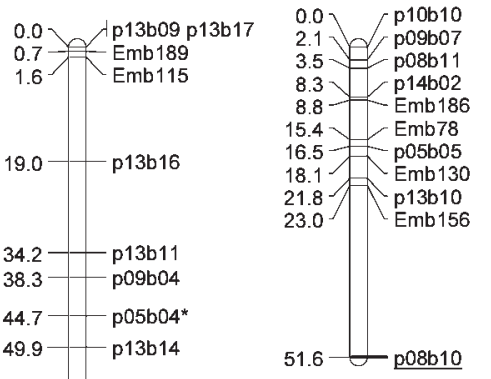

9

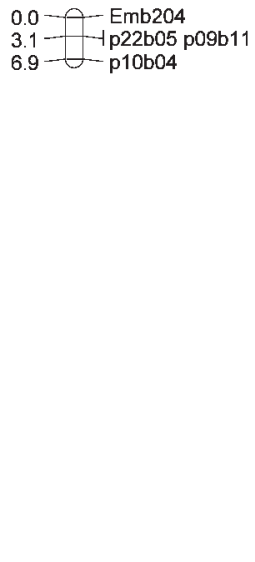

5

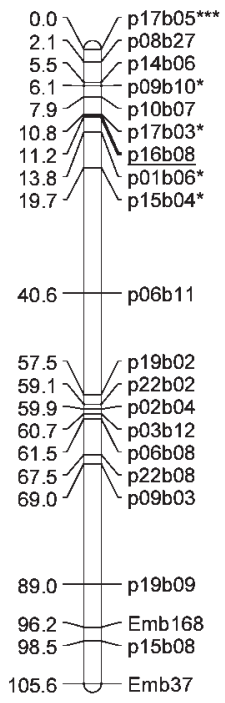

10

11

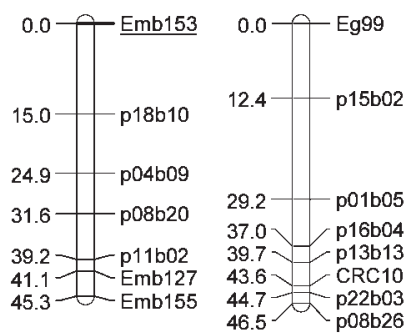

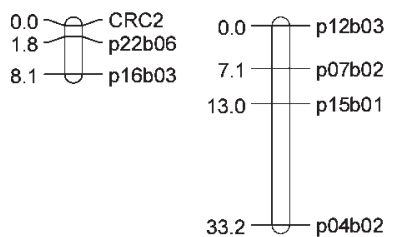

Figures 3(b). - Linkage map of the male parent. Group 2' corresponds to group 2 in the female and integrated maps. 
Table 3. - Number of loci mapped by segregation, marker type and source (for SSR). SSR markers that were fully informative could potentially be mapped in both parental maps as indicated by 'both' in the segregation column. Although, in some cases, a fully informative marker could only be mapped to one parent within the designated mapping parameters, causing some differences between the number of fully informative markers in parental and integrated maps.

\begin{tabular}{|c|c|c|c|c|c|c|}
\hline \multirow[b]{2}{*}{ Map } & \multirow[b]{2}{*}{ Segregation } & \multicolumn{3}{|c|}{ SSR } & \multirow[t]{2}{*}{ AFLP } & \multirow[t]{2}{*}{ Total } \\
\hline & & EMBRA & CSIRO & EMCRC & & \\
\hline \multirow[t]{3}{*}{ Male } & Male only & 3 & - & 1 & 79 & 83 \\
\hline & Both & 23 & 5 & 4 & 15 & 47 \\
\hline & Total & 26 & 5 & 5 & 94 & 130 \\
\hline \multirow[t]{3}{*}{ Female } & Female only & 1 & - & - & 68 & 69 \\
\hline & Both & 22 & 6 & 4 & 17 & 49 \\
\hline & Total & 23 & 6 & 4 & 85 & 118 \\
\hline \multirow[t]{4}{*}{ Integrated } & Male only & 3 & - & - & 63 & 66 \\
\hline & Female only & 1 & - & - & 55 & 56 \\
\hline & Both & 21 & 4 & 4 & 14 & 43 \\
\hline & Total & 25 & 4 & 4 & 132 & 165 \\
\hline
\end{tabular}

the AFLP marker p03b09 near the chromosome end, to lesser distortion in surrounding markers in both directions. Markers inherited solely from the male parent in this group were not distorted. Shared SSR markers in the equivalent group from the male parent exhibit distortion, however this was due to the deficiency of a maternal allele for all but one marker (EMCRC 8) in which there was no deficiency of alleles from either parent. The distortion can therefore be considered specific to the female parent. In contrast, in linkage group 5, segregation distortion was confined to markers inherited from the male parent (Figure $3 b$ ), with four markers near the groups extremity distorted at $\alpha \leq 0.05$.

\section{Discussion}

\section{Marker polymorphism}

Fifty three percent of amplifiable SSR loci screened in this study were fully informative (Table 2), compared with other reports in E. globulus of $60 \%$ in an $\mathrm{F}_{1}$ interprovenance cross (THAMARUs et al., 2002) and $34 \%$ in an $\mathrm{F}_{1}$ intraprovenance cross (BundOCK et al., 2000). The intraprovenance nature of the mapping cross employed by BunDOCK et al. (2000) may explain the lower proportion of polymorphism, compared to the interprovenance cross used herein.

The average of 12 polymorphic bands per AFLP primer combination in this study is low compared with other findings in eucalypts of 25 in an $\mathrm{F}_{1}$ interspecific cross of E. globulus and E. tereticornis (MARQUES et al., 1998 ) and 35 in a pseudo-backcross of E. globulus and $E$. grandis (MYBuRG et al., 2003). Two factors may account for these differences. Firstly, the interspecific crosses used by MARQUES et al. (1998) and MYBURG et al. (2003) are likely to produce a greater level of informative polymorphism than an intraspecific cross. Secondly, differences in the detection system employed for AFLP fragments may further account for differences in polymorphism between the studies. The sequencing gels employed for AFLP detection by MARQUES et al. (1998) and MYBURG et al. (2003), may provide increased resolution, allowing the detection of a greater number of bands per gel than the Gelscan 2000 employed in this study. However, the detection of fragments by Gelscan 2000 in conjunction with image analysis using Gene Profiler ${ }^{\mathrm{TM}}$ software allows substantially more rapid data collection, by reducing the duration of gel runs and allowing semiautomated scoring of fragments, relative to autoradiography and manual scoring as employed by MARQUES et al. (1998).

\section{Map construction}

The total map length of $701.9 \mathrm{cM}$ (integrated produced using 165 markers) in this study is low in comparison to other mapping efforts in Eucalyptus (see THAMARUs et al., 2002). At the upper limit, BYRNE et al. (1995) reported an integrated map length of $1462 \mathrm{cM}$ in $E$. nitens using 335 predominantly RFLP and RAPD markers, while at the lower limit MARQUES et al. (1998) reported a total map length of $919 \mathrm{cM}$ (female) and $967 \mathrm{cM}$ (male) in maps comprising 268 and 200 AFLP markers, respectively. An important factor contributing to the low map length herein is that the pair-wise mapping algorithm employed by Joinmap software consistently produces lower map lengths compared to multi-locus likelihood based packages (BUTCHER et al., 2002) such as Outmap (WILLIAMS and WHITAKER, 2001) and Mapmaker (LANDER et al., 1987). Incomplete map coverage in some linkage groups, due to the relatively low number of mapped markers in this study, may also contribute to the observed differences in map length (see evidence below). Furthermore, the presence of genotyping errors can overestimate the proportion of double crossovers, severely inflating map lengths (HACKETT and BROADFOOT, 2003). Therefore, the rigorous data checking and exclusion of numerous scored markers with an apparent excess of double crossovers may have had the effect of keeping map length to a minimum in this study.

There were more linkage groups than the haploid number of chromosomes in Eucalyptus (11), identified 
from cytological studies (reviewed in PoTTS and WILTSHIRE, 1997) for both the male (14 groups) and female (12 groups) maps. The finding of a greater number of linkage groups than chromosomes is not unusual in linkage studies (KESSELI et al., 1994; Wu et al., 2001), including eucalypts (BYRNE et al., 1995; MARQUES et al.,
1998). Such a discrepancy between the number of chromosomes and linkage groups can occur even with large numbers of mapped loci because the number of informative meiotic events required to reliably place markers in linkage groups is usually many times larger than the number of loci (EDWARDS, 1991). As a result, unlinked
1

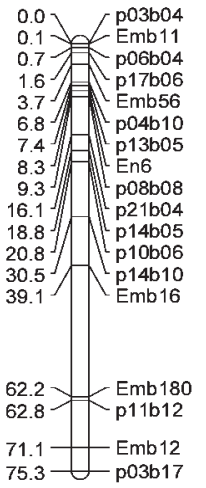

6

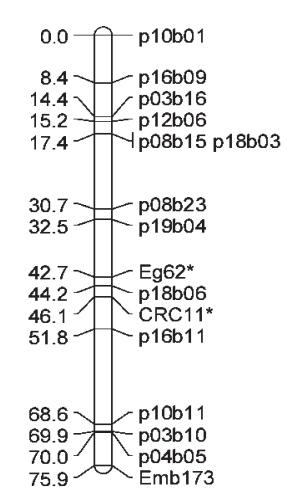

3

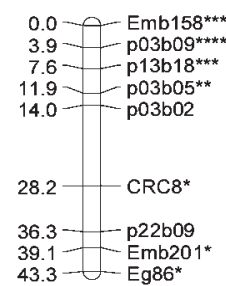
$43.3-\mathrm{Eg} 86^{*}$

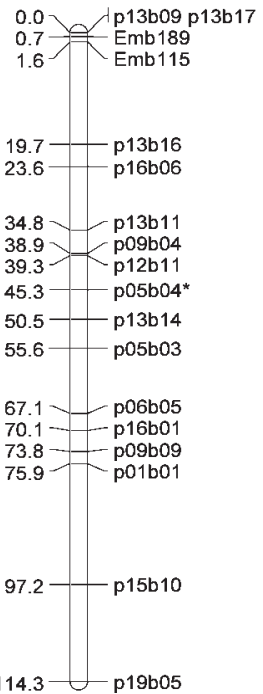

4

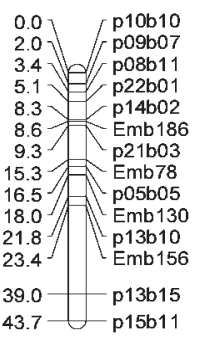

5

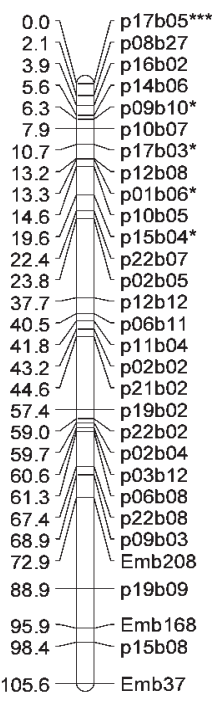

10
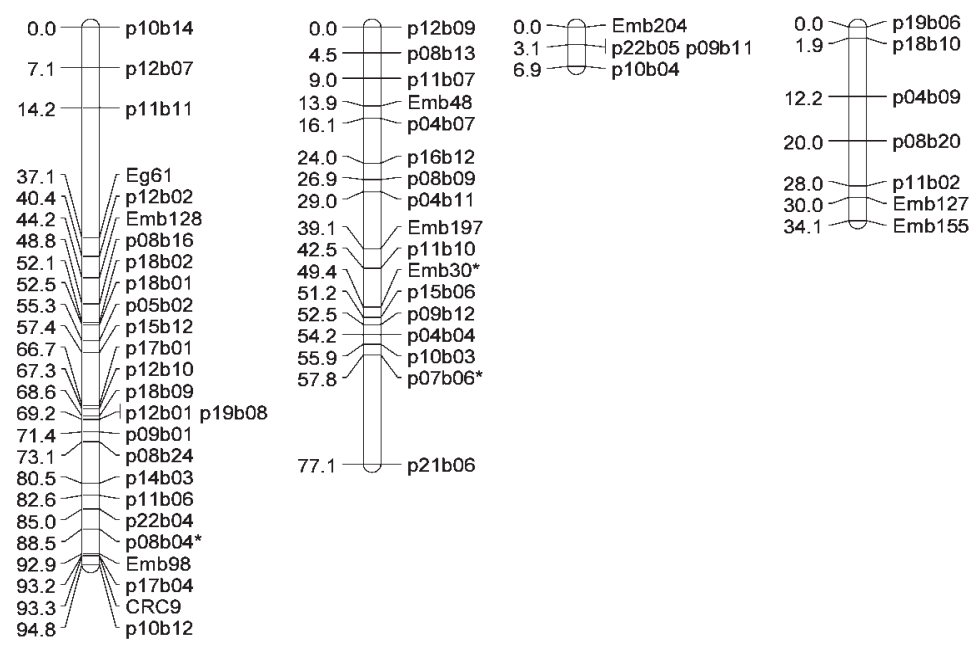

11

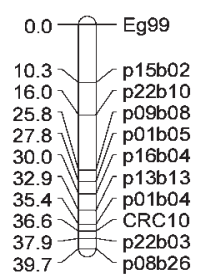

Figures 3(c). - Integrated linkage map. The integrated linkage map includes only framework markers that fit the order established from parental maps. Linkage group 9' was identified in the male parent only. 
markers and small linkage groups that could not be united with larger groups, were no doubt the cause of the greater number of linkage groups than chromosomes in parental maps within this study.

\section{Linkage group homology}

Comparative mapping studies rely on a set of common transferable markers that segregate in the species or pedigree of interest (AHUJA, 2001). Although various linkage maps have been constructed in eucalypts, the lack of transferability of markers commonly employed, such as RAPDs and AFLPs, means that linkage information and associated QTL data have been largely confined to the pedigrees used for map construction (GratTAPAGLIA, 2000). This deficiency of marker information has been a great hindrance to comparative mapping that would form the basis for the construction of a species wide consensus map, and more powerful QTL analysis in Eucalyptus (BRONDANI et al., 2002).

The ongoing development of numerous EMBRA SSR markers from Eucalypus grandis and E. urophylla has begun to address the problem of marker transferability (BRONDANI et al., 1998; 2002). For example, within the section Latoangulatae (BROOKER, 2000), 46 fully informative (EMBRA) SSR markers are common to linkage maps of both Eucalyptus grandis and E. urophylla (BRONDANI et al., 2002). Between sections, comparisons have largely been limited to markers with less information content or fewer SSR loci. For example, linkage information from Eucalyptus grandis and E. urophylla (section Latoangulatae; BRONDANI et al., 1998; GION et al., 2000) can be compared with $E$. globulus (section Maidenaria) based on 3 EMBRA loci and 5 lignin genes (THAMARUs et al., 2002) or 7 fully informative EMBRA loci (BuNDOCK et al., 2000). Similarly, linkage information from Eucalyptus camaldulensis (section Exsertaria; AGRAMA et al., 2002) can be compared with $E$. grandis and $E$. urophylla on the basis of 13 shared SSR markers (BRONDANI et al., 1998) and with E. globulus based on two (ThAmarus et al., 2002) and five (BundOcK et al., 2000) shared SSRs. The only study to date allowing comparison of synteny between sections in numerous SSR markers is that of MARQUES et al. (2002), which considered synteny of SSR loci and QTLs across Euca- lyptus grandis, E. urophylla, E. tereticornis (section Exsertaria) and E. globulus. MARQUES et al. (2002) reported only the homologies supported by at least 3 SSR loci in two different species, comprising 22 SSR across 8 linkage groups in E. globulus.

In an attempt to allow comparison between this and previous studies, 37 of the 41 SSR mapped herein were in common with other linkage studies in Eucalyptus. Importantly, this study included SSR loci developed from a variety of sources, allowing a wider comparability to other studies than was possible based solely on EMBRA markers (MARQUES et al., 2002). This included 27 EMBRA markers in common with BRONDANI et al. (1998, 2002, and unpublished data), three EMCRC and four EMBRA markers in common with BUNDOCK et al. (2000) and seven CSIRO markers in common with Thamarus et al. (2002).

The presence of 27 fully informative SSRs in common allowed all linkage groups identified by BRONDANI et al. (1998, 2002, and unpublished data) to be recognised in this pedigree (Table 4). Five linkage groups had three or more fully informative markers per group, allowing comparison of marker order. In agreement with past findings (THAMARUS et al., 2002; MARQUES et al., 2002; BuNDOCK et al., 2000), all linkage groupings of the EMBRA markers identified in a two way pseudo-testcross of E. grandis/urophylla (BRONDANI et al., 1998, 2002, and unpublished data), were preserved in the E. globulus maps in this study. However, a few minor inconsistencies in map distance and the order of markers were apparent. Permutations of marker order were evident in three of these five linkage groups. These involved mainly closely linked markers- EMBRA 208 and EMBRA 168 in linkage group 5 and EMBRA 127 and EMBRA 155, located at the end of linkage group 10. A more substantial difference occurs in linkage group 8 , where EMBRA 197 and EMBRA 48 differ in order relative to EMBRA 30 between maps of E. grandis / urophyl$l a$ and this study. Similarly, on linkage group 4, EMBRA 66 maps to the same position as EMBRA 130 in E. grandis/urophylla but is separated by $23 \mathrm{cM}$ in this study and is in a different position relative to EMBRA 186.

SSR markers shared between this study and maps produced by BuNDOCK et al. (2000), from an intraprove-

Table 4. - Linkage group homology. Linkage maps produced by BUNDOCK et al. (2000) had more linkage groups than the haploid number of chromosomes in Eucalyptus (11), hence linkage groups 9 and 1 in this study were equivalent to two linkage groups from BUNDOCK et al. (2000).

\begin{tabular}{cccl}
\hline $\begin{array}{c}\text { This study \& } \\
\text { Brondani et al. 1998, } \\
2002\end{array}$ & $\begin{array}{c}\text { Bundock et } \\
\text { al. }(2000)\end{array}$ & $\begin{array}{c}\text { Thamarus et al. } \\
(2002)\end{array}$ & $\begin{array}{c}\text { Candidate genes reported by } \\
\text { Thamarus et al. (2002) }\end{array}$ \\
\hline 1 & 4 and 5 & 7 & COMT \\
2 & & 4 & EAP1, PAL \\
3 & & 11 & MsaS2 \\
4 & 3 & 9 & AGE2 \\
5 & & 6 & EXS1 \\
6 & & 2 & CCoAOMT, ECA1 \\
7 & 6 & & \\
8 & 1 and 2 & & 4CL, AGE1, ELF1 \\
9 & & 3 & \\
10 & 13 & 3 &
\end{tabular}


nance cross of $E$. globulus, and THAMARUs et al. (2002), using an interprovenance $\mathrm{F}_{1}$ cross of $E$. globulus, both with parents originating from the same localities as those in this study (Table 4) allows tentative identification of homologous linkage groups. Homology between 5 linkage groups in this study and 7 linkage groups of BuNDOCK et al. (2000) are proposed on the basis of shared (EMBRA, and EMCRC) SSR. Only two homologous groups (corresponding to 3 groups from BuNDOCK et al., 2000) could be identified directly from shared markers, while the remaining homologies could be inferred by comparing EMBRA loci shared between each map and $E$. grandis / urophylla. This inference is justified as both this study and BuNDOCK et al. (2000), found complete agreement between linkage groupings with $E$. grandis / urophylla (BRONDANI et al., 1998, 2002, and unpublished data). However, in the case of BunDOCK et al. (2000) there where more linkage groups than chromosomes. As a result some linkage groups identified by BRONDANI et al. (1998) were equivalent to 2 linkage groups in the maps of BunDOCK et al. (2000). Additionally, there is a slight difference between the linkage groupings herein and those of BunDock et al. (2000). A single marker (EMCRC 9) maps to linkage group 7 in this study, but to a linkage group homologous to 9 in the study of BunDOCK et al. (2000; the linkage group nomenclature used by BuNDOCK et al. (2000), differs to that used in the present study (Table 4)).

The differences in marker order between this map and those produced by BRONDANI et al. (1998, 2002 and unpublished data) and BunDock et al. (2000) may represent actual differences caused by mechanisms such as chromosomal rearrangements between the mapping populations. Some evidence in support of chromosomal rearrangements between eucalypt species is provided by the fact that AGRAMA et al. (2002) also found a difference in marker order (in E. camaldulensis) compared with $E$. grandis and E. urophylla (BRONDANI et al., 1998) in the equivalent linkage group (8) to this study. Alternatively, amplification of non-target sites due to multiple copies of the same SSR loci, may have occurred as ERPELDING et al. (1996) found when transferring SSR between wheat and barley. On the other hand, the discrepancies may be artefacts of mapping imprecision. Because very few apparent recombinants can change map order, accurate ordering of closely linked markers is often problematic, requiring very large mapping populations (REMINGTON et al., 1999). Indeed practical limitations upon the number of individuals used in mapping populations of forest trees may account for the alternations in marker order which have occurred between parental maps produced in various tree species (MAliePAARD et al., 1998; Devey et al., 1999), including Eucalyptus (BRONDANI et al., 2002; MARQUES et al., 1998; 2002). At present, the number of comparable linkage maps produced in Eucalyptus species is insufficient to conclusively confirm or refute the occurrence of chromosomal rearrangements between species. Hence, further mapping using larger populations and more markers is required in E. globulus and other Symphyomyrtus species to clarify the nature and extent of any differences in marker order at both the interspecific and intraspecific levels.
When compared with the map of THAMARUs et al. (2002), all linkage groups of shared (CSIRO and EMBRA) SSR markers were conserved. Homology between 7 linkage groups of THAMARUs et al. (2002) and this study are inferred on the basis of 1 or 2 SSR in common per linkage group. However, there are some inconsistencies in the relative position of markers within linkage groups between maps. Specifically, the CSIRO marker Eg86 maps to the end of linkage group 2 herein, but a third of the way along the equivalent group in THAMARUs et al. (2002). Similarly, the CSIRO marker Eg99 maps to the end of the linkage group 11 herein but close to the middle of the equivalent linkage group in Thamarus et al. (2002). Similar discrepancies in the exact map location of specific markers have been noted previously in Eucalyptus (MARQUES et al., 1998; MYBURG et al., 2003; THAMARUs et al., 2002) and in the absence of evidence for chromosomal rearrangement are often attributable to sampling error (MYBURG et al., 2003) or differences in map coverage between studies. Incomplete map coverage of some linkage groups in the present study is the most likely cause of the above discrepancies.

\section{Segregation distortion}

The proportion of markers in this study displaying distortion from expected Mendelian segregation ratios is greater than would be expected by chance alone. For example, 12 markers from the male parent and 13 markers from the female parent exhibited segregation distortion (at $\alpha \leq 0.05$ ), clearly exceeding expectations for the male (6.5/130) and female (5.9/118) parents. The concentration of many of the distorted markers in two groups (male 5 and female 2) suggests a biological cause, rather than other potential factors, such as genotyping errors, that might produce an apparent distortion of segregation ratios (KEARSEY and POONI, 1996). The female group 2 is notable, in that all markers from this group are distorted and a gradient in the level of distortion from a maximum $(\alpha \leq 0.0001)$ in p03b09 occurs in this linkage group. Such departures from expected Mendelian segregation ratios have been widely documented in plants and animals (e.g. GILLET and GREGORIUS, 1992; BRADSHAW and STETTLER, 1994), including Eucalyptus (VAILlANCOURT et al., 1995; BundocK et al., 2000; MYBURG et al., 2003). Numerous mechanisms have been hypothesised to explain such distorted segregation ratios, operating at various stages of development (reviewed by GILleT and Gregorius, 1992). These include prezygotic mechanisms such as gametophytic incompatibility systems (e.g. GEBHARDT et al., 1991), meiotic drive (e.g. BUCKLER et al., 1999) and haploid expressed deleterious alleles and post-zygotic mechanisms such as the expression of genetic load (e.g. GION et al., 2000; BRADSHAW and SteTtLer, 1994) and hybrid incompatibility systems (e.g. RIESEBERG et al., 1995).

Gametophytic incompatibility systems reflect variable fertilisation success due to compatibility relations between gametic types and in most cases operate to exclude fertilisation by the male (GILLET and GREGORIUS, 1992). Gametophytic incompatibility is thus unlikely to account for the observed segregation distortion in the female linkage group 2. 
Ideally, a survey of allele frequencies before and after fertilisation would allow discrimination between segregation distortion due to pre-zygotic mechanisms such as meiotic drive and haploid expressed deleterious alleles and post-zygotic mechanisms such as genetic load (GILlet and Gregorius, 1992). Lacking such information, pre-zygotic mechanisms remain a possible cause of segregation distortion. However, the death of $\sim 25 \%$ of the planted $\mathrm{F}_{2}$ generation before they were sampled for this study suggests that some post-zygotic selection mechanism may well play a substantial role in distorting expected segregation ratios, as opposed to meiotic drive, haploid deleterious alleles or gametophytic incompatibility which would occur at the pre-zygotic stage. A close agreement between the number of individuals with the under represented genotype class in the most distorted markers from this group (p03b09 and p03b18) and the number of genotypes with at least one dead individual from the mapping population, is consistent with the effects of post-zygotic selective mechanisms (GILlet and Gregorius, 1992), such as genetic load or hybrid incompatibility.

The expression of genetic load involves the effects of deleterious or lethal alleles distorting segregation ratios of linked markers. Eucalypts are highly heterozygous and are known to carry many deleterious alleles in the heterozygous condition (POTTS and WILTSHIRE, 1997; PATTERSON et al., 2000). Such genes could possibly account for the observed segregation distortion from the female parent (group 2) in this study, as in VAILLANCOURT et al. (1995). Under this hypothesis, the distortion of the entire female linkage group 2 could be explained by one or several genes with a strong effect on viability segregating close to the markers where the distortion peaks, with diminishing effects toward the other extremity of the linkage group due to the effects of linkage.

Another possible post-zygotic mechanism contributing to segregation distortion is hybrid incompatibility resulting from the broad inter-provenance origin of the grandparents in the mapping pedigree. Trees from these locations are differentiated by nuclear microsatellites (PotTs et al., 2004) and as previously mentioned, are also classified into different geographical races on the basis of morphology (DUTKOwSKI and PoTTs, 1999). High levels of inviability have been noted in various interspecific hybrid combinations within Eucalyptus (reviewed by PotTs and Dungey, 2004). This process may also be applicable to broad intraspecific crosses such as the mapping pedigree in this study. For example, in an $\mathrm{F}_{1}$ (intraspecific) inter-provenance cross between $E$. globulus from King Island and Taranna, a reduced viability has been noted relative to an intra-provenance cross from King Island. However, the Taranna intra-provenance cross also performed poorly (VoLKER, 2002). Although most studies have demonstrated hybrid incompatibility in the $\mathrm{F}_{1}$ generation, barriers to hybridisation may also extend to further generations (outbreeding depression) as noted by PoTTs et al. (2000) where a reduced growth and survival of $E$. globulus by $E$. nitens affected $\mathrm{F}_{1}$ and $\mathrm{F}_{2}$ generations. Two general mechanisms are postulated to contribute to hybrid incompatibility, chromosomal rearrangements and genetic incompatibility between differentiated taxa (RIESEBERG et al., 1995). Genetic incompatibility may occur between differentiated populations of the same species due to processes such as the disruption of coadaptive gene complexes and the introduction of adaptive, or maladaptive genes (PoTTS et al., 2003). As previously discussed, there is as yet no conclusive evidence for gross chromosomal rearrangements in Eucalyptus at the intra- or interspecific level. Thus both general mechanisms remain possible causes of the observed segregation distortion in female linkage group 2.

\section{Conclusion}

The inclusion of numerous fully informative SSR, in conjunction with AFLP markers, has allowed the construction of parental and consensus maps in this pedigree of E. globulus. Mapping SSR markers derived from

Appendix. - Reaction conditions and segregation, for mapped SSR. Segregation: $a b \times c d=$ heterozygous in both parents with four alleles in total, $a b x$ ac $=$ heterozygous in both parents with three alleles in total, ab x cc = Male parent heterozygous, female parent homozygous with three alleles in total, ab $\mathrm{x}$ aa Male parent heterozygous, female parent homozygous with two alleles in total, aa $\mathrm{x}$ ab Female parent heterozygous, male parent homozygous with two alleles in total.

\begin{tabular}{|c|c|c|c|}
\hline Locus & $\mathrm{MgCl} 2(\mathrm{mM})$ & $\begin{array}{c}\text { Annealing } \\
\text { temperature }\left({ }^{\circ} \mathrm{C}\right)\end{array}$ & $\begin{array}{c}\text { Segregation } \\
\quad(\mathrm{M} \times \mathrm{F})\end{array}$ \\
\hline EMBRA 6 & 1.5 & 58 & $a b \times$ aa \\
\hline EMBRA 11 & 1.5 & 56 & $\mathrm{ab} \times \mathrm{cd}$ \\
\hline EMBRA 12 & 1.5 & 56 & $a b \times c d$ \\
\hline EMBRA 16 & 1.8 & 56 & $\mathrm{ab} \times \mathrm{cd}$ \\
\hline EMBRA 30 & 1.5 & 58 & $\mathrm{ab} \times \mathrm{cd}$ \\
\hline EMBRA 37 & 1.5 & 56 & $\mathrm{ab} \times \mathrm{cd}$ \\
\hline EMBRA 48 & 1.5 & 54 & $a b \times a c$ \\
\hline EMBRA 56 & 1.8 & 58 & $\mathrm{ab} \times \mathrm{cd}$ \\
\hline EMBRA 61 & 1.5 & 58 & $a b \times c d$ \\
\hline EMBRA 66 & 1.5 & 56 & $\mathrm{ab} \times \mathrm{cd}$ \\
\hline EMBRA 78 & 1.5 & 58 & $a b \times c c$ \\
\hline EMBRA 98 & 1.5 & 56 & $a b \times a c$ \\
\hline EMBRA 115 & 1.5 & 56 & $a b \times a c$ \\
\hline EMBRA 127 & 1.5 & 56 & $a b \times c d$ \\
\hline EMBRA 128 & 1.5 & 57 & $a b \times a c$ \\
\hline EMBRA 130 & 1.5 & 57 & $a b \times c d$ \\
\hline EMBRA153 & 1.5 & 57 & $a b \times a c$ \\
\hline EMBRA 155 & 1.5 & 60 & $a b \times a c$ \\
\hline EMBRA 156 & 1.5 & 59 & $a b \times c d$ \\
\hline EMBRA 158 & 1.5 & 56 & $a b \times a c$ \\
\hline EMBRA 168 & 1.5 & 60 & $a b \times a c$ \\
\hline EMBRA 173 & 1.5 & 55 & $a b \times c d$ \\
\hline EMBRA 180 & 1.5 & 56 & $a b \times a c$ \\
\hline EMBRA 186 & 1.5 & 57 & $a b \times a c$ \\
\hline EMBRA 189 & 1.5 & 56 & $a b \times c d$ \\
\hline EMBRA 197 & 1.5 & 56 & $a b \times a a$ \\
\hline EMBRA 201 & 1.5 & 58 & $a b \times a c$ \\
\hline EMBRA 204 & 1.5 & 56 & $a b \times a c$ \\
\hline EMBRA 208 & 1.5 & 58 & $a a \times a b$ \\
\hline CSIRO En6 & 1.5 & 55 & $a b \times c d$ \\
\hline CSIRO En10 & 2.0 & 50 & $a b \times a c$ \\
\hline CSIRO En16 & 1.5 & 55 & $a b \times c d$ \\
\hline CSIRO Eg61 & 2.0 & 50 & $a b \times a c$ \\
\hline CSIRO Eg62 & 2.0 & 48 & $a b \times c d$ \\
\hline CSIRO Eg86 & 2.0 & 55 & $a b \times c d$ \\
\hline CSIRO Eg99 & 1.5 & 55 & $a b \times a c$ \\
\hline EMCRC 2 & 2.0 & 55 & $a b \times a a$ \\
\hline EMCRC 8 & 2.0 & 55 & $a b \times c d$ \\
\hline EMCRC 9 & 2.0 & 55 & $a b \times c d$ \\
\hline EMCRC 10 & 2.0 & 55 & $a b \times c d$ \\
\hline EMCRC 11 & 2.0 & 55 & $a b \times c d$ \\
\hline
\end{tabular}


a variety of sources has demonstrated almost complete homology in linkage groupings across a range of Symphyomyrtus species, encompassing multiple sections, although some minor differences in the distance and order of markers within linkage groups were apparent. Further mapping within E. globulus using an expanded set of SSR markers will clarify the nature and extent of any differences between Symphyomyrtus species, paving the way for further comparative mapping and ultimately consensus maps of the subgenus. The low success in transfer of SSR loci from E. grandis/urophylla, from which most SSR in Eucalyptus have been developed, suggests that more SSRs will be required in order to produce high coverage maps in E. globulus based exclusively on these markers. Segregation distortion of some markers has been demonstrated, concentrated in two gender specific groups. In the case of the severe distortion in the female group 2, post zygotic mechanisms are a likely cause.

\section{Acknowledgements}

We would like to thank KeLSEY JOYCE and Gunns Ltd. for access to the trial site. The Australian Research Council and the Cooperative Research Centre for Sustainable Production Forestry for financial assistance. DARIO GRATTAPAGLIA and ROSANI BRONDANI for providing SSR primers. PAUL TILYARD for assistance collecting foliage samples. REBECCA JONES and ADAM SMOLENSKI for technical assistance and DoROTHY STEANE for comments on the manuscript.

\section{References}

Agrama, H. A., T. L. George and S. F. Salah (2002): Construction of genome map for Eucalyptus camaldulensis DEHN. Silvae Genetica 51: 201-206.

AHUJA, M. R. (2001): Recent advances in molecular genetics of forest trees. Euphytica 121: 173-195.

AvISE, J. C. (1994): Molecular markers, natural history and evolution. Chapman and Hall International, New York.

Bradshaw, H. D. and R. F. Stettler (1994): Molecular genetics of growth and development in Populus II. Segregation distortion due to genetic load. Theoretical and Applied Genetics 89: 551-558.

Brondani, R. P. V., C. Brondani, R. TARChini and D. GratTAPAGLIA (1998): Development, characterization and mapping of microsatellite markers in Eucalyptus grandis and Eucalyptus urophylla. Theoretical \& Applied Genetics 97: 816-827.

Brondani, R. P. V. (2001): Development, characterization and mapping of microsatellite markers in Eucalyptus. $\mathrm{PhD}$ thesis, University of Brasília, Brazil.

Brondani, R. P. V., C. Brondani and D. Grattapaglia (2002): Towards a genus-wide reference linkage map for Eucalyptus based exclusively on highly informative microsatellite markers. Molecular Genetics \& Genomics 267: 338-347.

Brooker, M. I. H. (2000): A new classification of the genus Eucalyptus L'Hér. (Myrtaceae). Australian Systematic Botany 13: 79-148.

Buckler, E. S., T. L. Phelps-Durr, C. S. Keith Buckler, R. Kelly Dawe, J. F. Doebley and T. P. Holtsford (1999): Meiotic drive of chromosomal knobs reshaped the maize genome. Genetics 153: 415-426.
Bundock, P. C., M. HAYden and R. E. VAILlancourT (2000): Linkage maps of Eucalyptus globulus using RAPD and microsatellite markers. Silvae Genetica 49: 223-232.

Butcher, P. A., E. R. Williams, D. Whitaker, S. Ling, T. P. SPEed and G. F. MoRAN (2002): Improving linkage analysis in outcrossed forest trees - an example from Acacia mangium. Theoretical and Applied Genetics 104: 1185-1191.

Byrne, M., J. C. Murrell, B. Allen and G. F. Moran (1995): An integrated genetic linkage map for eucalypts using RFLP, RAPD and isozyme markers. Theoretical and Applied genetics 91: 869-875.

Byrne, M., M. I. Marques-Garcia, T. Uren, D. S. Smith and G. F. Moran (1996): Conservation and genetic diversity of microsatellite loci in the genus Eucalyptus. Australian Journal of Botany 44: 331-341.

Carnegie, A. J., P. J. Keane, P. K. Ades and I. W. Smith (1994): Variation in susceptibility of Eucalyptus globulus provenances to Mycosphaerella leaf disease. Canadian Journal of Forest Research 24: 1751-1757.

Cervera, M. T., C. Plomion and C. Malpica (2000): Molecular markers and genome mapping in woody plants, pp. 375-394. In: Molecular biology of woody plants, edited by JaIn, S. M. and Minocha, S. C., Volume 1, Kluwer Academic Publishers, Netherlands.

Cervera, M. T., V. Storme, B. Ivens, J. Gusmão, B. H. Liu, V. Hostyn, J. V. Slycken, M. V. Montagu and W. BoerJAN (2001): Dense genetic linkage maps of three Populus species (Populus deltoides, P. nigra and P. trichocarpa) based on AFLP and microsatellite markers. Genetics 158: 787-809.

Devey, M. E., M. M. Sewell, T. L. URen and D. B. Neale (1999): Comparative mapping in loblolly and radiata pine using RFLP and microsatellite markers. Theoretical \& Applied Genetics 99: 656-662.

Doyle, J. J. and J. L. Doyle (1990): Isolation of plant DNA from fresh tissue. Focus 12, 13-15.

Dutkowski, G. W. and B. M. PotTs (1999): Geographic patterns of genetic variation in Eucalyptus globulus ssp. globulus and a revised racial classification. Australian Journal of Botany 47: 237-263.

EDWARDS, J. H. (1991): The reliability of locus orderings. Annals of Human Genetics 55: 315-320.

EldRIDGe, K., J. Davidson, C. HARWOOD and G. VAN WYK (1993): Eucalypt domestication and breeding. Oxford University Press, New York.

Erpelding, J. E., N. K. Blake, T. K. Blake and L. E. TalBERT (1996): Transfer of sequence tagged site PCR markers between wheat and barley. Genome 39: $802-810$

Gebhardt, C., E. Ritter, E. Barone, T. Debener, B. Walkemeier, U. Schachtschnabel, H. Kaufmann, R. D. Thompson, M. W. Boneirbale, M. W. Ganal, S. D. TANKSLEY and F. SALAMINI (1991): RFLP maps of potato and their alignment with the homologous tomato genome. Theoretical and Applied Genetics 83: 49-57.

Gillet, E. and H.-R. Gregorius (1992): What can be inferred from open pollinated progenies about the source of observed segregation distortion? - A case study in Castanea sativa Mill. Silvae Genetica 41: 82-87.

Gion, J.-M., P. Rech, J. Grima Pettenati, D. Verhaegen and C. Plomion (2000): Mapping candidate genes in Eucalyptus with emphasis on lignification genes. Molecular Breeding 6: 441-449. 
GrattaPAGLiA, D. (1997): Opportunities and challenges for the incorporation of genomic analysis in Eucalyptus breeding, pp. 129-136. In: Silviculture and Improvement of Eucalypts, Proceedings IUFRO Conference, Salvador, Brazil.

GRATtAPAGLIA, D. (2000): Molecular breeding of Eucalyptus, pp. 451-474. In: Molecular biology of woody plants, edited by JAIN, S. M. and Minocha, S. C., Volume 1, Kluwer Academic Publishers, Netherlands.

Grattapaglia, D. and R. SEderofF (1994): Genetic linkage maps of Eucalyptus grandis and Eucalyptus urophylla using a pseudo-testcross mapping strategy and RAPD markers. Genetics 137: 1121-1137.

Gupta, V., A. Mukhopadhyay, N. Arumugam, Y. S. Sodhi and A. K. Pradhan (2004): Molecular tagging of erucic acid trait in oilseed mustard (Brassica juncea) by QTL mapping and single nucleotide polymorphisms in FAE1 gene. Theoretical and Applied Genetics 108: 743-749.

HACKeTt, C. A. and L. B. BRoAdFoOT (2003): Effects of genotyping errors, missing values and segregation distortion in molecular marker data on the construction of linkage maps. Heredity 90: 33-38.

Jones, M. E., R. L. Stokoe, M. J. Cross, L. J. Scott, T. L. MAGuire and M. Shepherd (2001): Isolation of microsatellite loci from spotted gum (Corymbia variegata), and cross-species amplification in Corymbia and Eucalyptus. Molecular Ecology Notes 1: 276-278.

Kearsey, M. J. and H. S. Pooni (1996): The genetical analysis of quantitative traits. Chapman and Hall, London.

Keats, B. J. B., S. L. Sherman, N. E. Morton, E. B. Robson, K. H. Buetow, P. E. Cartwright, A. Chakravarti, U. Francke, P. P. Green and J. OTt (1991): Guidelines for human linkage maps - an International System for Human Linkage Maps (ISLM 1990). Annals Human Genetics 55: 1-6.

Kesseli, R., I. PARAN and R. W. Michelmore (1994): Analysis of a detailed genetic linkage map of Lactuca sativa (Lettuce) constructed from RFLP and RAPD markers. Genetics 136: 1435-1446.

Lander, E. S., P. Green, J. Abrahamson, A. Barlow, M. J. DALY, S. E. Lincoln and L. NewbuRG (1987) Mapmaker: an interactive computer package for constructing primary genetic linkage maps of experimental and natural populations. Genomics 1: 174-181.

MALIEPAARD, C., F. H. Alston, G. van Arkel, L. M. Brown, E. Chevreau, F. Dunemann, K. M. Evans, S. Gardiner, P. Guilford, A. W. van Heusden, J. Janse, F. Laurens, J. R. Lynn, A. G. Manganaris, A. P. M. DEN NiJs, N. Periam, E. RikKerink, P. Roche, C. RYder, S. Sansavini, H. Schmidt, S. Tartarini, J. J. Verhaegh, M. VRIELINK-VAN GiNGEL and G. J. KING (1998): Aligning male and female linkage maps of apple (Malus pumila Mill.) using multi-allelic markers. Theoretical and Applied Genetics 97: 60-73.

Marques, C. M., J. A. Araujo, J. G. Ferriera, R. WhetTEN, D. M. OMalley, B. H. Liu and R. Sederoff (1998): AFLP genetic maps of Eucalyptus globulus and E. tereticornis. Theoretical and Applied Genetics 96: 727-737.

Marques, C. M., R. P. V. Brondani, D. Grattapaglia and R. SEDEROFF (2002): Conservation and synteny of SSR loci and QTLs for vegetative propagation in four Eucalyptus species. Theoretical and Applied Genetics 105: 474-478.

Myburg, A. A., D. L. Remington, D. M. O’Malley, R. R. Sederoff and R. W. Whetten (2001): Highthroughput AFLP analysis using infrared dye-labeled primers and an automated DNA sequencer. BioTechniques 30: 348-357.

Myburg, A. A., A. R. Griffin, R. R. Sederoff and R. W. WHETTEN (2003): Comparative genetic linkage maps of Eucalyptus grandis, Eucalyptus globulus and their $\mathrm{F}_{1}$ hybrid based on a double pseudo-backcross mapping approach. Theoretical and Applied Genetics 107: 1028-1042.

Patterson, B., C. M. Wolbang, R. E. Vaillancourt and B. M. PotTs (2000): Inheritance of two chlorophyll mutants in Eucalyptus globulus. Silvae Genetica 49: 290-291.

Plomion, C., N. Bahrman, C. Durel and D. M. O’Malley (1995): Genomic mapping in Pinus pinaster (maritime pine) using RAPD and protein markers. Heredity 74: 661-668.

Potts, B. M. and R. J. E. Wiltshire (1997): Eucalypt genetics and genecology, pp 56-91. In: Eucalypt ecology: individuals to ecosystems, edited by WILLIAMS, J., Woinarski, J., Cambridge University Press, Cambridge.

Potts, B. M., P. W. Volker, P. A. Tilyard and K. Joyce (2000): The genetics of hybridisation in the temperate Eucalyptus. pp. 200-210. In: Dungey, H. S., Dieters, M. J., NikLes, D. G. (eds) Hybrid Breeding and Genetics of Forest Trees, Proceedings of QFRI/CRC-SPF Symposium, Noosa, Queensland, Australia.

Potts, B. M., R. C. Barbour, A. B. Hingston and R. E. VAILlAnCOURT (2003): Turner Review no. 6, Genetic pollution of native eucalypt gene pools-identifying the risks. Australian Journal of Botany 51: 1-25.

PotTs, B. M. and H. S. Dungey (2004): Interspecific hybridization of Eucalyptus: key issues for breeders and geneticists. New Forests 27: $115-138$.

Potts, B. M., R. E. Vaillancourt, G. Jordan, G. Dutkowski, J. Costa e Silva, G. McKinnon, D. Steane, P. Volker, G. Lopez, L. Apiolaza, Y. Li, C. Marques and N. BorralHo (2004): Exploration of the Eucalyptus globulus gene pool. Plenary paper, pp 46-61. In: BoRRalho, N., Periera, J. S., Marques, C., Coutinho, J., Madeira, M., Tome, M. (eds) Eucalyptus in a changing world. Proceedings IUFRO Conference. RAIZ, Instituto Investigação de Floresta e Papel, Aveiro, Portugal.

Remington, D. L., R. W. Whetten, B. H. LiU and D. M. O'MALLEY (1999): Construction of an AFLP genetic map with nearly complete genome coverage in Pinus taeda. Theoretical and Applied Genetics 98: 1279-1292.

RieseberG, L. H., C. R. Linder and G. J. Seiler (1995): Chromosomal and genic barriers to introgression in Helianthus. Genetics 141: 1163-1171.

Shepherd, M., M. Cross, M. J. Dieters and R. Henry (2003): Genetic maps for Pinus elliottii var. elliottii and P. caribaea var. hondurensis using AFLP and microsatellite markers. Theoretical and Applied Genetics 106: 1409-1419.

Sewell, M. M. and D. B. Neale (2000): Mapping quantitative traits in forest trees, pp 407-423. In: Molecular biology of woody plants, edited by JAIN, S. M. and Minocha, S. C., Volume 1, Kluwer Academic Publishers, The Netherlands.

Steane, D. A., R. E. Vaillancourt, J. Russell, W. Powell and D. MARshall and B. M. PotTs (2001): Development and characterisation of microsatellite loci in Eucalyptus globulus (Myrtaceae). Silvae Genetica 50: 89-91.

Thamarus, K. A., K. Groom, J. Murrell, M. Byrne and G. F. Moran (2002): A genetic linkage map for Eucalyptus globulus with candidate loci for wood, fibre, and floral traits. Theoretical \& Applied Genetics 104: 379-387. 
Vaillancourt, R. E., B. M. Potts, A. Manson, T. Eldridge and J. B. REID (1995): Using RAPDs to detect QTLs in an interspecific $\mathrm{F}_{2}$ hybrid of Eucalyptus. pp 430-433. In: Potts, B. M., Borralho, N. M. G., Reid, J. B., Cromer, R. N., TibBits, W. N. and RAYMOND, C. A. (eds) Eucalypt plantations: Improving fibre yield and quality. Proceedings papers CRC IUFRO conference, Hobart, Australia.

VAN OOIJEN, J. W. and R. E. VoORRIPS (2001): Joinmap ${ }^{\circledR}$ 3.0, software for the calculation of genetic linkage maps. Plant Research International, Wageningen, the Netherlands.

Verhaegen, D. and C. Plomion (1996): Genetic mapping in Eucalyptus urophylla and Eucalyptus grandis using RAPD markers. Genome 39: 1051-1061.

VOLKER, P. W. (2002): Genetics of Eucalyptus globulus, $E$. nitens and $\mathrm{F}_{1}$ hybrid. $\mathrm{PhD}$ Thesis, University of Tasmania, Australia.
Vos, P., R. Hogers, M. Bleeker, M. Reijans, T. Van De Lee, M. Hornes, A. Frijters, J. Pot, J. Peleman, M. KUIPER and M. ZABEAU (1995): AFLP: a new technique for DNA fingerprinting. Nucleic Acids Research 23: 4407-4414.

WiLliAMs, E. R. and D. WHITAKER (2001): Outmap ${ }^{\odot} 1.0$, a package for genetic mapping, CSIRO forestry and forest products, Canberra, Australia and University of Waikato, Hamilton, New Zealand.

Wu, R. L., Y. F. Han, J. J. Hu, J. J. FANG, L. Li, M. L. Li and Z. B. ZENG (2001): An integrated genetic map of Populus deltoides based on amplified fragment length polymorphisms. Theoretical \& Applied Genetics 100: 1249-1256.

\title{
Genetic Variation and Correlations between Growth and Wood Density of Calycophyllum spruceanum at an Early Age in the Peruvian Amazon
}

\author{
By C. Sotelo Montes ${ }^{1), *)}$, R. E. Hernández ${ }^{1)}$, J. Beaulied ${ }^{2)}$ and J. C. Weber ${ }^{3)}$
}

(Received $17^{\text {th }}$ February 2006)

\begin{abstract}
Calycophyllum spruceanum (Benth.) Hook. f. ex K. Shum. is an important timber-tree species in the Peruvian Amazon Basin. As farmers and industry often use wood from young trees, it is important to investigate variation in juvenile wood properties in this species. A provenance/progeny test was established to evaluate genetic variation in growth and wood properties of young trees, the strength of their genetic control as well as their interrelationships both at the genetic and the phenotypic level in different planting zones. In this paper, results are presented for tree height and stem diameter (near ground level) at 16, 28 and 39 months; and stem diameter and basic density of the wood at breast height at 39 months. Significant variation due to provenances and especially due to families within provenances was found in growth and wood density. Phenotypic and genetic correlations indicated that larger trees tended to have denser wood. Wood density had higher heritability than height and diameter; and genetic con-
\end{abstract}

1) Centre de recherche sur le bois, Pavillon Gene Kruger, Université Laval, Québec (Québec), G1K7P4, Canada.

2) Natural Resources Canada, Canadian Forest Service, Fibre Centre, 1055 du P.E.P.S., P.O. Box 10380, Stn. Sainte-Foy, Quebec, Quebec, G1V4C7, Canada.

${ }^{3}$ ) World Agroforestry Centre (ICRAF), B.P. 320, Bamako, Mali; and Adjunct Professor, Faculty of Forestry and Geomatics, Laval University.

*) Author for correspondence: Telephone: 418-656-5852, fax: 418656-2091. E-mail: soteloc@hotmail.com trol over height, diameter and density was generally highest in the planting zone where trees grew most rapidly.

Key words: provenance, family, environment, heritability, phenotypic and genetic correlations, juvenile wood.

\section{Introduction}

The Peruvian Amazon has many valuable timber-tree species, but there has been little research on genetic variation in these species. Farmers and industry commonly use juvenile wood, and they will probably use it even more in the future with the promotion of agroforestry and small-scale plantation forestry. Tree breeders, therefore, should initiate research on genetic variation in properties of juvenile wood to see whether it is possible to improve them through breeding work and to measure the impact of selection for juvenile wood traits on other traits (ZoBEL and SPRAGUE, 1998).

Calycophyllum spruceanum (Benth.) Hook. f. ex K. Shum. (Rubiaceae family) is a pioneer species that colonizes the floodplain and disturbed forests in the Amazon Basin (LinARES et al., 1992). The breeding system has not been studied, but is assumed to be primarily outcrossing like the majority of tropical trees (BAWA et al., 1990). Trees have hermaphroditic flowers, and mature in 2 to 3 years in open-grown conditions. There is probably extensive gene flow, producing high levels of genetic variation within populations and relatively low genetic 